\title{
A Comparison of Post-Operative Occlusion with 3-D vs. 2-D Miniplate Fixation in the Management of Isolated Mandibular Angle Fractures
}

\author{
Anosha Mujtaba ${ }^{1}$, Namrah Rafiq Malik ${ }^{2}$, Muhammad Farooq Umer ${ }^{3,4, *(D)}$, Hasan Mujtaba ${ }^{5, *}$, \\ Shumaila Zofeen ${ }^{6}$ iD and Zahoor Ahmad Rana ${ }^{1}$
}

check for

updates

Citation: Mujtaba, A.; Malik, N.R.; Umer, M.F.; Mujtaba, H.; Zofeen, S.; Rana, Z.A. A Comparison of Post-Operative Occlusion with 3-D vs. 2-D Miniplate Fixation in the Management of Isolated Mandibular Angle Fractures. J 2022, 5, 107-113. https://doi.org/10.3390/j5010008

Academic Editors: Jon Øyvind Odland and Maria Luisa Balestrieri

Received: 29 November 2021

Accepted: 29 January 2022

Published: 2 February 2022

Publisher's Note: MDPI stays neutral with regard to jurisdictional claims in published maps and institutional affiliations.

Copyright: (C) 2022 by the authors. Licensee MDPI, Basel, Switzerland. This article is an open access article distributed under the terms and conditions of the Creative Commons Attribution (CC BY) license (https:// creativecommons.org/licenses/by/ $4.0 /)$.
1 Department of Oral and Maxillofacial Surgery, School of Dentistry, FMTI, Islamabad 44080, Pakistan; anoshamujtaba@gmail.com (A.M.); rajput8@yahoo.com (Z.A.R.)

2 Department of Community and Preventive Dentistry, Watim Dental College Rawat, Islamabad 45900, Pakistan; rafiqnamrah@gmail.com

3 Alshifa School of Public Health, Alshifa Trust, Jhelum Road, Rawalpindi 46200, Pakistan

4 Department of Epidemiology, Health Services Academy University, Chak Shahzad, Islamabad 44000, Pakistan

5 School of Dentistry, Shaheed Zulfiqar Ali Bhutto Medical University, Islamabad 44080, Pakistan

6 School of Public Health, Xi'an Jiaotong University, Xi'an 710061, China; shumailazofeen@yahoo.com

* Correspondence: rafooq@hotmail.com (M.F.U.); h_mujtaba@outlook.com (H.M.)

\begin{abstract}
Mandibular angle fractures (MAFs) are treated in a variety of ways; however, the standard therapy is still up for debate. Despite the fact that many studies have generated evidence for the appropriate biomechanical stability of 3-D miniplates, there is an insufficient amount of data on the treatment of mandibular angle fractures with these plates. A comparative study was conducted at The Department of Oral and Maxillofacial Surgery, Pakistan Institute of Medical Sciences (PIMS), Islamabad. Patients were randomly divided into two groups of 52 patients each. Patients in group A were treated with 3-D miniplate placement on the lateral cortex following the principle of 3-D fixation proposed by Farmand and Dupoirieux, whereas patients included in group B were treated using 2-D conventional miniplate, placed according to Champy's line of ideal osteosynthesis. A single surgical team performed the procedure. On the first and seventh post-operative days, the first month, and then the third month after surgery, regular evaluations were conducted. Assessment regarding Post Open Reduction and Internal Fixation (ORIF) occlusion was performed with the help of measuring tools. On the first day post-operative follow-up, 41 (78.8\%) patients in group A and $31(59.6 \%)$ patients in group B had satisfactory occlusion. The seventh day post-operative follow-up showed that $43(82.7 \%)$ patients in group A and $41(78.8 \%)$ patients in group B had satisfactory occlusion $(p>0.05)$. In both treatment groups, the first and third month follow-up evaluations revealed optimal occlusion. In comparison to conventional 2-D miniplate, the 3-D miniplate system produced better results and can be recommended as a better option for the management of mandibular angle fractures.
\end{abstract}

Keywords: mandibular; angle; fractures; 3-D; 2-D; conventional; miniplate; management; isolated

\section{Introduction}

Mandible holds an essential role in the maxillofacial region in terms of both function and appearance. Males are more likely to suffer from mandibular fractures than females [1,2]. Fractures of the mandible constitute $15.5-59 \%$ of all fractures of the face $[3,4]$. Esthetic and socially compromised disabilities are caused by fractures of the mandible [5]. Pertaining to the etiology of mandibular fractures, studies have often shown that road traffic accidents (RTAs) are the main cause for most of the patients reporting with mandibular fractures, other factors are physical attacks, sports injuries, and falls [6,7]. The characteristic of mandibular angle fractures (MAFs) is that a fracture line starts around the most anterior edge of the mandibular ramus and connects with the mandible, usually around the area of 
the third molar [8,9]. MAFs are common mandibular fractures, accounting for nearly $25 \%$ of mandibular fractures [10]. This repetitive association of the mandibular angle region in fractures, including the face, may be due to a thinner cross-sectional region, the presence of third molars, and the angle being exposed to strong muscular forces [8]. MAFs create more complex fracture related injuries than any other mandibular fracture. The treatment of mandibular angle fractures requires precise knowledge of the surgical framework, muscle insertion, associated biomechanical loads and their effect on the angle, as well as the presence of a third mandibular molar in the fracture line $[8,10,11]$. The literature reports a variety of techniques for managing mandibular angle fractures, including closed reduction with maxillomandibular fixation, transosseous wire, lag screw, and open reduction with plate osteosynthesis [12]. At present, miniplate internal fixation has become the standard treatment for mandibular angle fractures. The advantages of open reduction and internal fixation include early repair of occlusal function and correct fracture reduction [13]. About a decade ago, the use of miniplates and monocortical screws for the two-point fixation of angle fractures was widely recommended, but compared with single-point fixation, the complication rate was much higher [14,15]. Thus, the single miniplate used according to Champy's principles has developed into the standard procedure for angle fractures in various units $[16,17]$. Recently, reservations regarding the lack of three-dimensional stability of the traditional miniplate fixation of mandibular angle fractures have become the focus of debate among surgeons. This is based on current clinical and experimental studies, where many authors have attributed inferior border splaying to loading forces applied near the fracture line, posterior open bite on the side of the fracture, wound dehiscence, and infection $[18,19]$. These limitations led to the development of 3-D miniplates. This plating system was proposed by Mostafa Farmand in 1992 for the treatment of maxillofacial fractures [20]. It is conjectured that a single matrix miniplate offers functional stability desired for the fixation with minimal operative time and a comparatively lower complication rate [21]. The shape of the 3-D strut plate theoretically increases the number of screws, allowing for 3-D stability and resistance to torque forces while maintaining thinness and malleability $[15,21]$. However, there is just a small number of studies available in the literature on 3-D miniplate fixation, in contrast with the customary 2-D miniplate fixation technique. Particularly, in Pakistan, no substantial work on 3-D miniplates has been carried out to this point.

Henceforth, based on this little information, there is no consensus on whether one method is better than the other. Therefore, this study aims to evaluate the clinical application of 3-D titanium miniplates and traditional 2-D miniplates in the open reduction and internal fixation of isolated MAFs.

\section{Materials and Methods}

A comparative study was performed at the department of Oral and Maxillofacial Surgery, PIMS Hospital, Islamabad, from February 2018 to February 2019. Sample size was calculated by using the WHO sample size calculator. The inclusion and exclusion criteria were defined as follows:

Patients who met the inclusion criteria (Table 1) were recruited from the department of Oral and Maxillofacial Surgery PIMS. Informed, written consent was taken. Demographic data was recorded on the Proforma. Patients were randomly allocated into group A and group B, each having 52 patients. Patients in group A were treated with 3-D miniplate placement on the lateral cortex following the three-dimensional principle fixation of Farmand and Dupoirieux (Figure 1), whereas group B were treated with a 2-D conventional miniplate placed along Champy's line of osteosynthesis (Figure 2). Fractures were treated by open reduction under general anesthesia. The fracture site was accessed either intraorally or transbuccally, contingent on the location of the fracture and the access extent. Procedure was performed by a single surgical team. Temporary intraoperative maxillomandibular fixation was established with the eyelet wires. Third molar in the line of fracture was removed during the surgery, if indicated, i.e., if fractured, carious, or causing hindrance in reduction 
of fracture segments. MMF was released after reducing and fixing the fracture. Both the groups were prescribed antibiotics Injection Amoxicillin/clavulanic acid 1.2 g I/V BD, Inj. Metronidazole $500 \mathrm{mg}$ I/V TDS, and analgesics (Diclofenac Sodium $75 \mathrm{mg}$ I/M) BD for five days. Patients were advised to use a soft diet and maintain strict oral hygiene. Patients remained admitted in the ward for three days depending upon the condition of patients. All patients were assessed on the first day, seventh day, first month, and third month postoperatively to evaluate post ORIF occlusion by using a divider and caliper between the upper and lower first molar and was categorized as satisfactory (no gap), mildly deranged (1-2 mm gap), and deranged ( $>2 \mathrm{~mm}$ gap). Findings were recorded on the proforma. Data collected were entered in Statistical Package for Social Sciences (SPSS) version 25.0. and results were analyzed. Chi-squared test analysis was used for all statistical comparisons. A $p$-value of 0.05 was arbitrarily taken to be significant.

Table 1. Inclusion and exclusion criteria.

\begin{tabular}{cc}
\hline Inclusion Criteria & Exclusion Criteria \\
\hline $\begin{array}{c}\text { Patients above 16 years diagnosed with } \\
\text { isolated mandibular angle fractures }\end{array}$ & Previously treated mandibular angle fractures \\
& Infected fractures \\
Comminuted fractures \\
Completely edentulous patients \\
Medically compromised patients
\end{tabular}

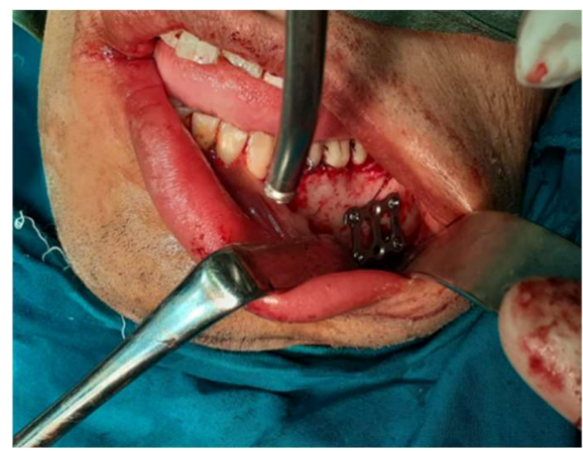

Figure 1. Pre-op picture of patient with 3D miniplate.

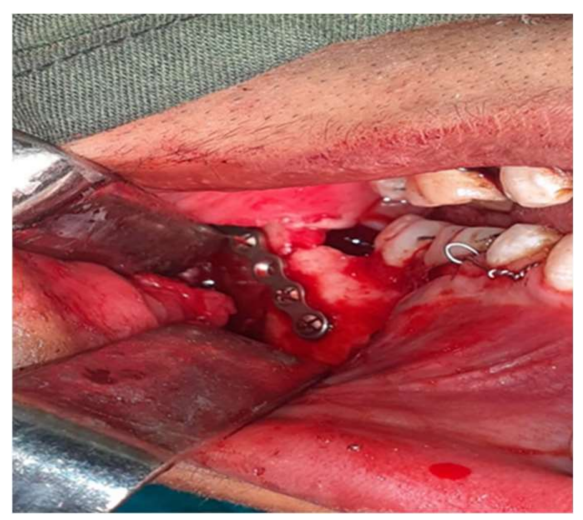

Figure 2. Pre-op picture of patient with 2-D miniplate.

\section{Results}

The age of the patients in the present study ranged from 16 to 60 years. Table 2 describes that the majority of patients were in the 16-30 years age group $(n=70,67.3 \%)$, while the least number of patients were in the $41-60$ years age group $(n=5,4.8 \%)$. Out of the 104 patients in this study, there were 72 men $(69.2 \%)$ and 32 women (30.8\%). In 
group A, there were $30(57.7 \%)$ male and $22(42.3 \%)$ female patients. In group B, there were $42(80.8 \%)$ male and $10(19.2 \%)$ female patients. RTAs were reported to be the most frequent cause of the angle fractures $(n=58,55.8 \%)$. This was followed by falls $(n=36$, $34.6 \%)$ and assault $(n=10,9.6 \%)$. After day 1,72 cases were reported to be satisfactory, 27 were mildly deranged, and five cases were reported to be deranged in both groups collectively. Table 3 represents that in group A, 41 cases were found to have satisfactory occlusion, as compared to 31 cases in group B having satisfactory occlusion. Furthermore, 10 patients from group A had mildly deranged occlusion, in comparison to 17 cases in group $B$ having mildly deranged occlusion. The differences in the frequency distribution of occlusion at day 1 between groups A and B were not found to be significant $(p>0.05)$. At day 7, in group A, 43 cases were found to have satisfactory occlusion, as compared to 41 cases in group B having satisfactory occlusion. Furthermore, nine patients from group A had mildly deranged occlusion, in comparison to 11 cases in group B having mildly deranged occlusion. At the first and third months, all 104 patients were reported to have satisfactory occlusion (The changes during course of study have been shown in Figure 3).

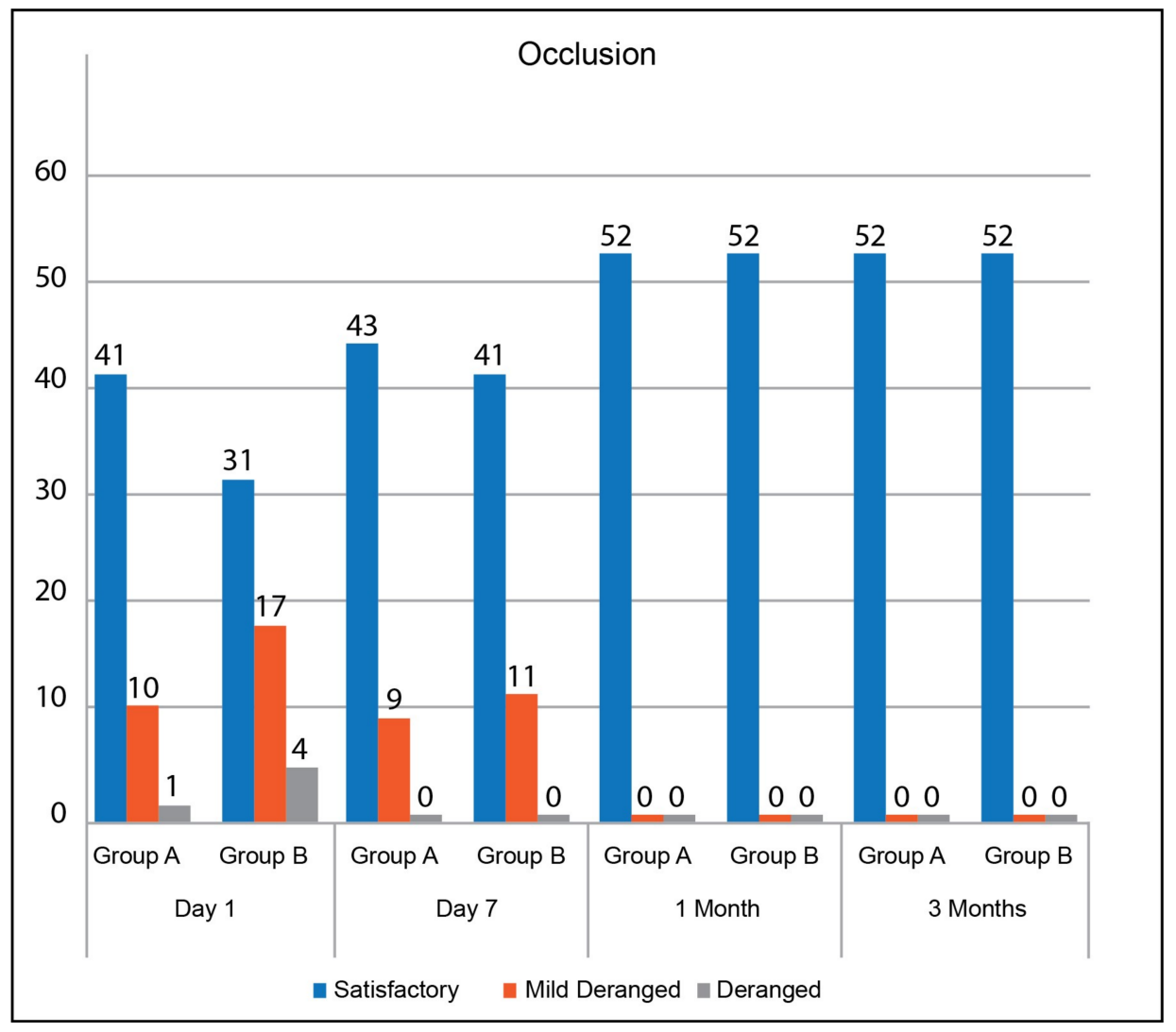

Figure 3. Occlusion in group A and group B over the 4 time intervals.

Table 2. Demographic data $(n=104)$.

\begin{tabular}{ccccc}
\hline \multicolumn{5}{c}{ Gender Distribution } \\
\hline Males & Group A & Group B & Total & $p$-Value \\
Females & $30(57.7 \%)$ & $42(80.8 \%)$ & $72(69.2 \%)$ & 0.02 \\
\hline \multicolumn{5}{c}{ Etiology of Fractures } \\
\hline Fall & $22(42.3 \%$ & $10(19.2 \%)$ & $32(30.8)$ & 0.01 \\
RTA & $28(53.8 \%)$ & $8(15.4 \%)$ & $36(34.6 \%)$ & \\
Assault & $20(38.5)$ & $38(73.1 \%)$ & $58(55.8 \%)$ & $10(9.6 \%)$ \\
\hline
\end{tabular}


Table 2. Cont.

\begin{tabular}{ccccc}
\hline \multicolumn{5}{c}{ Age Group } \\
\hline $16-30$ & $27(51.9 \%)$ & $43(82.7 \%)$ & $70(67.8 \%)$ & 0.01 \\
$31-40$ & $22(42.3 \%)$ & $7(13.5 \%)$ & $29(27.9)$ & \\
$41-60$ & $3(5.8 \%)$ & $2(3.8 \%)$ & $5(4.8 \%)$ & \\
Total & $52(100 \%)$ & $52(100 \%)$ & $104(100 \%)$ & \\
\hline
\end{tabular}

Table 3. Occlusion $(n=104)$.

\begin{tabular}{|c|c|c|c|c|}
\hline & Group A & Group B & Total & $p$-Value \\
\hline \multicolumn{5}{|c|}{ Occlusion Day 1} \\
\hline Satisfactory & $41(78.8 \%)$ & $31(59.6 \%)$ & $72(69.2 \%)$ & \multirow{3}{*}{0.11} \\
\hline $\begin{array}{l}\text { Mildly } \\
\text { Deranged }\end{array}$ & $10(19.2 \%)$ & $17(32.7 \%)$ & $27(26.0 \%)$ & \\
\hline Deranged & $1(1.9 \%)$ & $4(7.7 \%)$ & $5(4.8 \%)$ & \\
\hline \multicolumn{5}{|c|}{ Occlusion Day 7} \\
\hline Satisfactory & $43(82.7 \%)$ & $41(78.8 \%)$ & $84(80.8 \%)$ & \\
\hline $\begin{array}{c}\text { Mildly } \\
\text { Deranged }\end{array}$ & $9(17.3 \%)$ & $11(21.2 \%)$ & $20(19.2 \%)$ & 0.62 \\
\hline Deranged & 0 & 0 & 0 & \\
\hline Total & $52(100 \%)$ & $52(100 \%)$ & $104(100 \%)$ & \\
\hline
\end{tabular}

\section{Discussion}

The geometry of the 3-D plate permits three dimensional stability and opposes torque forces while ensuring a low profile and malleability [22]. A three-dimensional plate is a modification of Champy's system in which two plates are connected by vertical bars, neutralizing tension and compression forces at the same time [23]. The present study compared the effectiveness of the 3-D miniplate system, in comparison to the 2-D miniplate system, for the treatment of isolated mandibular angle fractures in terms of achieving balanced dental occlusion.

This study reported road traffic accidents to be the most common cause of mandibular angle fractures $(n=58,55.8 \%)$, followed by falls $(n=36,34.6 \%)$ and assault $(n=10$, $9.6 \%)$. However, the most common etiological factor for mandibular angle fractures in the developed world is assault in males and road traffic accidents in females [24]. The possible reason for this could be the high volume of accidents in Pakistan. This suggests that the social, cultural, and environmental risk factors affecting the occurrence of mandibular angle fractures differ from one country to another. Data from the developed world reports men to be more likely to suffer from mandibular fractures (70-85\%) [25]. Similarly, our study also reported $72(69.2 \%)$ cases in men, as compared to $32(30.8 \%)$ cases in women. Mandibular angle fractures are observed in the second and third decades in the developed world [26]. Our study reported $70(67.3 \%)$ mandibular angle fracture cases in the 16-30 years age group and $29(27.9 \%)$ cases in the 31-40 years age group. This increased susceptibility of fractures, associated with gender and age range, could possibly be explained by the increased likelihood of interpersonal violence and road traffic accidents in these groups. The present study reported a total of 32 (30.8\%) cases which had either mildly deranged or deranged occlusion after the first post-operative day. Out of these 32 cases, $11(21.1 \%)$ patients were treated with 3-D plates, while 2-D plates were placed in $21(40.4 \%)$ cases. These findings suggest that, after the first post-operative day, the malocclusion was reported in a significantly greater number of patients in whom 2-D plates were placed, as compared to those in whom 3-D plates were placed. However, by the end of the first week, the difference in the malocclusion between the two groups was not significant $(p=0.62)$. This difference in initial stability could be attributed to the comparatively better interfragmentary strength of the 3-D miniplates. Vineeth et al. compared the effectiveness of a single compression miniplate and 3-D miniplate in a sample of 30 patients with mandibular angle 
fractures. The difference in malocclusion between the two groups was reported to be statistically significant $(p<0.05)$ : patients with 3-D plates reported to have better occlusion results [27]. Al Tairi reported a $100 \%(n=8)$ occlusion rate for patients treated using 3-D plates for mandibular angle fractures. An occlusion rate of $87.5 \%(n=7)$ was reported for patients treated with 2-D plates [28]. A systematic review by Al-Moraissi reported fewer complication rates for 3-D plates in comparison to 2-D plates for managing mandibular angle fractures based on better interfragmentary stability [29]. Similarly, a meta-analysis by Wusiman depicted a lower incidence of malocclusion with a 3-D miniplate fixation as compared to the 2-D miniplate [30]. The results of our study strongly substantiate the findings of these reviews in suggesting the better performance of 3-D plates in the treatment of isolated mandibular angle fractures. However, there were certain limitations in the present study. First, the difference in age, gender, surgical approach, and presence of a third molar would affect the outcome post-operatively. Second, post-operative complications other than malocclusion were not included in the study. Therefore, there is a need for further studies with a larger sample size to compare the two techniques effectively.

\section{Conclusions}

The present study provides significant evidence to suggest that initial occlusion achieved after the fixation of mandibular angle fractures using 3-D plates is better compared to cases in which 2-D plates are used. These findings can be used to inform guidelines on the benefit of the use of 3-D plates in the management of MAF.

Author Contributions: A.M. and Z.A.R. conceptualized the idea, A.M., S.Z. and N.R.M. recruited the patients, A.M. and Z.A.R. performed the procedure, M.F.U., N.R.M., S.Z. and H.M. performed the data analysis, M.F.U. and H.M. revised the study protocol, All the authors drafted the manuscript, Z.A.R. supervised the research. All authors have read and agreed to the published version of the manuscript.

Funding: This research received no external funding.

Institutional Review Board Statement: The study was conducted according to the guidelines of the Shaheed Zulfiqar Ali Bhutto Medical University (SZABMU) and approved by the Ethics Review Board of SZABMU on 04-10-2017 (No. F.1-1/2015/ERB/SZABMU).

Informed Consent Statement: Informed consent was obtained from all subjects involved in the study.

Data Availability Statement: Data shall be available to the editor on a reasonable request.

Conflicts of Interest: The authors declare no conflict of interest.

\section{References}

1. Maurer, P.; Eckert, A.W.; Kriwalsky, M.S.; Schubert, J. Scope and limitations of methods of mandibular reconstruction: A long-term follow-up. Br. J. Oral Maxillofac. Surg. 2010, 48, 100-104. [CrossRef] [PubMed]

2. Qiamuddin. Analysis of 362 cases of maxillofacial injuries in northern region of Pakistan. Pak. Oral Dent. J. 1991, $11,35-43$.

3. Kim, K.; Ibrahim, A.M.S.; Koolen, P.G.L.; Lee, B.T.; Lin, S.J. Trends in Facial Fracture Treatment Using the American College of Surgeons National Surgical Quality Improvement Program Database. Plast. Reconstr. Surg. 2014, 133, 627-638. [CrossRef] [PubMed]

4. Vyas, A.; Mazumdar, U.; Khan, F.; Mehra, M.; Parihar, L.; Purohit, C. A study of mandibular fractures over a 5-year period of time: A retrospective study. Contemp. Clin. Dent. 2014, 5, 452-455. [CrossRef]

5. Sehgal, S.; Ramanujam, L.; Prasad, K.; Krishnappa, R. Three-dimensional v/s standard titanium miniplate fixation in the management of mandibular fractures-A randomized clinical study. J. Cranio-Maxillofac. Surg. 2015, 42, 1292-1299. [CrossRef]

6. Amjad, S.; Adnan Ali, S.; Abdus, S. Pattern and management of mandibular fractures: A study conducted on 264 patients. Pak. Oral Dent. J. 2007, 27, 103-106.

7. Gadicherla, S.; Sasikumar, P.; Gill, S.S.; Bhagania, M.; Kamath, A.T.; Pentapati, K.C. Mandibular Fractures and Associated Factors at a Tertiary Care Hospital. Arch. Trauma Res. 2016, 5, e30574. [CrossRef]

8. Tiwari, A.; Lata, J.; Mishra, M. Influence of the impacted mandibular third molars on fractures of the mandibular angle and condyle-A prospective clinical study. J. Oral Biol. Craniofacial Res. 2016, 6, 227-230. [CrossRef]

9. Al-Moraissi, E.A.; Ellis, E. What Method for Management of Unilateral Mandibular Angle Fractures Has the Lowest Rate of Postoperative Complications? A Systematic Review and Meta-Analysis. J. Oral Maxillofac. Surg. 2014, 72, 2197-2211. [CrossRef]

10. Lee, J.-H. Treatment of Mandibular Angle Fractures. Arch. Craniofacial Surg. 2017, 18, 73-75. [CrossRef] [PubMed] 
11. Zanakis, S.; Tasoulas, J.; Angelidis, I.; Dendrinos, C. Tooth in the line of angle fractures: The impact in the healing process. A retrospective study of 112 patients. J. Cranio-Maxillofac. Surg. 2015, 43, 113-116. [CrossRef] [PubMed]

12. Danda, A.K. Comparison of a Single Noncompression Miniplate Versus 2 Noncompression Miniplates in the Treatment of Mandibular Angle Fractures: A Prospective, Randomized Clinical Trial. J. Oral Maxillofac. Surg. 2010, 68, 1565-1567. [CrossRef] [PubMed]

13. Andreasen, J.O.; Jensen, S.S.; Kofod, T.; Schwartz, O.; Hillerup, S. Open or closed repositioning of mandibular fractures: Is there a difference in healing outcome? A systematic review. Int. Assoc. Dent. Traumatol. 2008, 24, 17-21. [CrossRef]

14. Tams, J.; van Loon, J.-P.; Otten, B.; Bos, R.R. A computer study of biodegradable plates for internal fixation of mandibular angle fractures. J. Oral Maxillofac. Surg. 2001, 59, 404-407. [CrossRef]

15. Zhu, W. Failure Analysis of the Superior Lateral Plate Technique for Mandibular Angle Fractures. J. Oral Maxillofac. Surg. 2019, 77, 107-108. [CrossRef]

16. Champy, M.; Loddé, J.; Schmitt, R.; Jaeger, J.; Muster, D. Mandibular osteosynthesis by miniature screwed plates via a buccal approach. J. Maxillofac. Surg. 1978, 6, 14-21. [CrossRef]

17. Yazdani, J.; Talesh, K.T.; Hosein, M.; Motamedi, K.; Fekri, S.; Hajmohammadi, S. Mandibular Angle Fractures: Comparison of One Miniplate vs. Two Mini- plates. Trauma Mon. 2013, 18, 17-20. [CrossRef]

18. Alkan, A.; Çelebi, N.; Özden, B.; Baş, B.; Inal, S. Biomechanical comparison of different plating techniques in repair of mandibular angle fractures. Oral Surg. Oral Med. Oral Pathol. Oral Radiol. Endodontol. 2007, 104, 752-756. [CrossRef]

19. Sadhwani, B.S.; Anchlia, S. Conventional $2.0 \mathrm{~mm}$ miniplates versus 3-D plates in mandibular fractures. Ann. Maxillofac. Surg. 2013, 3, 154-159. [CrossRef]

20. Farmand, M.; Dupoirieux, L. The value of 3-dimensional plates in maxillofacial surgery. Rev. De Stomatol. Et De Chir. MaxilloFaciale 1992, 93, 353-357.

21. Singh, R.K.; Chand, S.; Pal, U.S.; Das, S.K.; Sinha, V.P. Matrix miniplate versus locking miniplate in the management of displaced mandibular angle fractures. Natl. J. Maxillofac. Surg. 2013, 4, 225-228. [CrossRef]

22. Wusiman, P.; Taxifulati, D.; Weidong, L.; Moming, A. Three-dimensional versus standard miniplate, lag screws versus miniplates, locking plate versus non-locking miniplates: Management of mandibular fractures, a systematic review and meta-analysis. J. Dent. Sci. 2019, 14, 66-80. [CrossRef]

23. Bohner, L.; Beiglboeck, F.; Schwipper, S.; Lustosa, R.M.; Segura, C.P.M.; Kleinheinz, J.; Jung, S. Treatment of Mandible Fractures Using a Miniplate System: A Retrospective Analysis. J. Clin. Med. 2020, 9, 2922. [CrossRef] [PubMed]

24. Erdmann, D.; Follmar, K.E.; DeBruijn, M.; Bruno, A.D.; Jung, S.-H.; Edelman, D.; Mukundan, S.; Marcus, J.R. A Retrospective Analysis of Facial Fracture Etiologies. Ann. Plast. Surg. 2008, 60, 398-403. [CrossRef] [PubMed]

25. Gutta, R.; Tracy, K.; Johnson, C.; James, L.E.; Krishnan, D.G.; Marciani, R.D. Outcomes of Mandible Fracture Treatment at an Academic Tertiary Hospital: A 5-Year Analysis. J. Oral Maxillofac. Surg. 2014, 72, 550-558. [CrossRef] [PubMed]

26. Schierle, H.P.; Schmelzeisen, R.; Rahn, B. Experimental studies of the biomechanical stability of different miniplate configurations for the mandibular angle. Kiefer Gesichts-Chir. 1996, 41, 166-170.

27. Vineeth, K.; Lalitha, R.M.; Prasad, K.; Ranganath, K.; Shwetha, V.; Singh, J. “A comparative evaluation between single noncompression titanium miniplate and three dimensional titanium miniplate in treatment of mandibular angle fracture"-A randomized prospective study. J. Cranio-Maxillofac. Surg. 2013, 41, 103-109. [CrossRef]

28. Al-Tairi, N.; Shoushan, M.; Khedr, M.S.; Abd-Alal, S. Comparison of three-dimensional plate versus double miniplate osteosynthesis for treatment of unfavorable mandibular angle fractures. Tanta Dent. J. 2015, 12, 89-98. [CrossRef]

29. Al-Moraissi, E.; Mounair, R.; El-Sharkawy, T.; El-Ghareeb, T. Comparison between three-dimensional and standard miniplates in the management of mandibular angle fractures: A prospective, randomized, double-blind, controlled clinical study. Int. J. Oral Maxillofac. Surg. 2015, 44, 316-321. [CrossRef]

30. Wusiman, P.; Nie, B.; Li, W.D.; Moming, A. Management of mandibular angle fractures using 3- dimensional or standard miniplates: A systematic review and meta-analysis. J. Cranio-Maxillofac. Surg. 2019, 47, 622-628. [CrossRef] 